Regular Article

\title{
Elevated plasma neutrophil elastase concentration is associated with disease activity in patients with thrombotic thrombocytopenic purpura
}

\author{
Bálint Mikes a , György Sinkovits a , Péter Farkas a , Dorottya Csuka a , Ágota Schlammadinger ${ }^{\mathrm{b}}$, Katalin Rázsó b \\ Judit Demeter ${ }^{c}$, Gyula Domján ${ }^{c}$, Marienn Réti ${ }^{\mathrm{d}}$, Zoltán Prohászka ${ }^{\mathrm{a}, *}$ \\ a 3rd Department of Internal Medicine, Semmelweis University, Budapest, Hungary \\ b 2nd Department of Internal Medicine, University of Debrecen, Debrecen, Hungary \\ c 1 st Department of Internal Medicine, Semmelweis University, Budapest \\ d Department of Hematology and Stem Cell Transplantation, St István and St László Hospital, Budapest
}

\section{A R T I C L E I N F O}

\section{Article history:}

Received 21 October 2013

Received in revised form 7 January 2014

Accepted 27 January 2014

Available online 1 February 2014

\section{Keywords:}

Polymorphonuclear leukocyte

neutrophil granulocyte

elastase

thrombotic thrombocytopenic purpura

disease activity

complement activation

\begin{abstract}
A B S T R A C T
Introduction: Genetic and autoimmune risk factors contribute to the development of thrombotic thrombocytopenic purpura (TTP) but triggers are needed to bring about acute disease.

The aim of the study was to investigate the association of neutrophil activation with acute TTP, to assess whether neutrophil activation changes during plasma exchange therapy and to show if complement- and neutrophil activation are parallel, characteristic processes in acute TTP.

Materials and Methods: Altogether 49 EDTA-plasma samples of 21 TTP patients with acute disease and 17 in remission were investigated along with 20 healthy controls.

A stable complex of PMNE-proteinase-inhibitor was measured by ELISA (Calbiochem, Merck-Millipore, Darmstadt, Germany).

Results: Acute disease was associated with significantly increased PMNE levels, the group medians were similarly low in TTP patients in remission and in healthy controls. Increased PMNE levels were characteristic for hematologically active and ADAMTS13 deficient form of TTP. PMNE concentration inversely correlated to disease activity markers platelet count $(\mathrm{r}=-0.349, \mathrm{p}=0.032)$ and hemoglobin levels $(\mathrm{p}=-0.382 \mathrm{p}=0.018)$. Achievement of remission was associated with significant reduction of plasma PMNE levels ( $p=0.031$, Wilcoxon test). There was positive correlation between PMNE levels and complement activation markers C3a and $\mathrm{Bb}$. Conclusions: We report increased PMNE levels in acute TTP and showed its association to activity markers of acute TTP and complement activation. Effective treatment of an acute TTP episode resulted in marked decrease in PMNE levels. Our data support and extend previous observations that neutrophil extracellular traps may be released in acute TTP and potentially contribute to the pathophysiology of this disease.
\end{abstract}

(c) 2014 Elsevier Ltd. All rights reserved.

\section{Introduction}

Various etiological factors represent increased risk for the development of thrombotic thrombocytopenic purpura (TTP), a life-threatening disorder. Characteristic clinical features of TTP are microangiopathic hemolytic anemia, thrombocytopenia and various involvements of other organs, for example the kidneys and the nervous system [1,2]. In most cases development of functional inhibitors (autoantibodies) against the von Willebrand factor (VWF) cleaving protease (A Disintegrin and Metalloproteinase with ThromboSpondin-1 like motifs-13, ADAMTS13) predispose to disease. Inherited variations of ADAMTS13 may also confer increased risk of TTP development, whereas a minor part of TTP patients presents with non-ADAMTS13 deficient disease form [3]. Severe deficiency of ADAMTS13 leads to the increased presence of unusually

\footnotetext{
* Corresponding author at: H-1125 Budapest, Kútvölgyi st. 4. Tel.: + 361 3251379, + 36 20 8250962; fax: + 3612253899

E-mail address: prohoz@kut.sote.hu (Z. Prohászka).
}

large multimers of VWF that promote the formation of platelet rich thrombi in the capillaries and small vessels leading to tissue ischemia and organ failure [4].

However, ADAMTS13 deficient patients may remain asymptomatic for several years $[5,6]$. Furthermore, several patients may go into sustained clinical remission despite deficient ADAMTS13 activity [7,8]. In addition, although patients with acute TTP often present without acute disease in history, in the majority of TTP patients infections or pregnancy precede the acute disease flare [9]. These well-known clinical observations collectively indicate that multiple hits may be necessary for the development of clinically active TTP, and ADAMTS13 deficiency, even though it is probably the most important predisposing risk factor, it is alone not sufficient to cause acute TTP.

Previously our group reported on the presence of complement activation in patients with acute TTP [10] an observation recently confirmed in an independent cohort [11]. Our data indicated that activation of the classical/lectin and alternative pathways that lead to the activation of the terminal pathway was present in TTP. It is known 
that activation of the complement system and of neutrophil granulocytes is characteristic for most infections and also in pregnancy, especially if complicated with preeclapmsia and/or fetal growth restriction [12,13]. Therefore, we hypothesized that neutrophil activation may associate with acute, ADAMTS13-deficient TTP and potentially contribute to the development of clinically active thrombotic microangiopathy. Supporting this hypothesis were results of a recent study showing increased circulating DNA and myeloperoxidase levels in patients suffering from thrombotic microangiopathies (TMAs) [14]. Hence, the aim of the current study was to formally investigate the association of neutrophil activation with acute TTP, to assess whether neutrophil activation changes during plasma exchange therapy and to show if complementand neutrophil activation are parallel, characteristic processes in acute TTP.

\section{Materials and Methods}

\section{Patients and Plasma Samples}

Thirty-eight patients with TTP were enrolled in this single-research laboratory based investigation providing diagnostic services (ADAMTS13 and complement measurements) since August, 2007 for patients suspected to have HUS or TTP in Hungary. The patient enrolment for this study was closed in January, 2011. The criteria used to guide patient stratification, diagnosis and sample selection have been described in details [10]. Briefly, diagnosis of TTP was based on one or more episodes of Coombs-negative microangiopathic hemolytic anemia with thrombocytopenia defined as serum lactate dehydrogenase (LDH) $>450 \mathrm{U} / \mathrm{L}$; fragmented erythrocytes in the peripheral blood smear and platelet count $<150 \mathrm{G} / \mathrm{L}$; only patients with severely decreased ADAMTS13 activity levels $(<5 \%)$, or history of it, were included in this study. Patients with acute oligo-anuric renal failure were excluded from the study. Hematological remission (HR) was determined when platelet counts were $>150 \mathrm{G} / \mathrm{L}$ on two consecutive days without any sign of hemolysis even if there were any neurological, renal or other residual clinical symptoms, whereas complete remission (CR) was established when, platelet count remained above the lower limit continuously for at least 1 month.

Table 1 shows clinical and laboratory data of the cohort who had available plasma samples for the current study. Using samples of this TTP cohort we measured plasma polymorphonuclear cell elastase (PMNE) levels during acute disease flare, in remission, and for comparison in controls. Samples of 38 TTP patients have been investigated. Twenty-one patients with acute disease (mean age 40 years, SD 15, 17 women), 17 TTP patients in remission (mean age 42 years, SD 10, 14 women) and 20 healthy age- and sex matched controls (mean age 35 years, SD 17, 15 women) were enrolled. Eight patients with acute

Table 1

Clinical and laboratory data of the 38 patients with thrombotic thrombocytopenic purpura.

\begin{tabular}{|c|c|c|c|c|c|c|c|c|c|c|}
\hline $\begin{array}{l}\text { Registry } \\
\text { code }\end{array}$ & $\begin{array}{l}\text { Age at } \\
\text { blood } \\
\text { sampling } \\
\text { (years) }\end{array}$ & Sex & $\begin{array}{l}\text { Acute/ } \\
\text { Remission }\end{array}$ & $\begin{array}{l}\text { ADAMTS13 activity } \\
\text { of patient's sample } \\
\text { (FRETS-VWF73); } \\
\text { reference } \\
\text { range } 67-147 \%\end{array}$ & $\begin{array}{l}\text { ADAMTS13 activity } \\
\text { of mixed sample } \\
\text { (patient's plasma } \\
\text { with pooled plasma 1:1) } \\
\text { (FRETS-VWF73); reference } \\
\text { range }>50 \% \text { of the daily } \\
\text { control sample }\end{array}$ & $\begin{array}{l}\text { Hemoglobin; } \\
\text { reference ranges, } \\
\text { females } 123-153 \mathrm{~g} / \mathrm{L} \text {, } \\
\text { males } 140-175 \mathrm{~g} / \mathrm{L}\end{array}$ & $\begin{array}{l}\text { Platelets; } \\
\text { reference range } \\
150-400 \mathrm{G} / \mathrm{L}\end{array}$ & $\begin{array}{l}\text { White Blood } \\
\text { Cells; reference } \\
\text { range 4-10 G/L }\end{array}$ & $\begin{array}{l}\text { Absolute } \\
\text { neutrophil } \\
\text { count; } \\
\text { reference } \\
\text { range } 2.12 \text { - } \\
7.5 \mathrm{G} / \mathrm{L}\end{array}$ & $\begin{array}{l}\text { PMN elastase } \\
\text { proteinase } \\
\text { inhibitor } \\
\text { complex } \\
(\mathrm{ng} / \mathrm{mL})\end{array}$ \\
\hline HUN1 & 26 & $\mathrm{~F}$ & Acute & $\mathbf{0}$ & $\mathbf{0}$ & 80 & 33 & 31,50 & 25,51 & 3,10 \\
\hline HUN15 & 55 & M & Acute & $\mathbf{0}$ & $\mathbf{0}$ & 108 & 22 & 12,06 & 10,61 & 0,82 \\
\hline HUN23 & 38 & M & Acute & $\mathbf{0}$ & 30 & 91 & 45 & 6,40 & 3,21 & 0,63 \\
\hline HUN43 & 62 & $\mathrm{~F}$ & Acute & $\mathbf{0}$ & 26 & 72 & 28 & 6,53 & 5,68 & 0,53 \\
\hline HUN50 & 17 & $\mathrm{~F}$ & Acute & $\mathbf{0}$ & 9 & 76 & 17 & 11,20 & 7,71 & 2,72 \\
\hline HUN56 & 44 & $\mathrm{~F}$ & Acute & $\mathbf{0}$ & $\mathbf{0}$ & 83 & 44 & 6,81 & 4,44 & 0,57 \\
\hline HUN62 & 35 & $\mathrm{~F}$ & Acute & $\mathbf{0}$ & 11 & 81 & 18 & 11,63 & 9,13 & 1,76 \\
\hline HUN68 & 43 & M & Acute & 5 & 6 & 64 & 9 & 6,30 & 4,38 & 1,15 \\
\hline HUN72 & 13 & $\mathrm{~F}$ & Acute & $\mathbf{0}$ & $\mathbf{0}$ & 72 & 84 & 10,80 & 8,48 & 5,61 \\
\hline HUN76 & 57 & $\mathrm{~F}$ & Acute & $\mathbf{0}$ & 23 & 85 & 30 & 7,11 & 5,02 & 2,46 \\
\hline HUN85 & 49 & $\mathrm{~F}$ & Acute & 0 & $\mathbf{0}$ & 85 & 31 & 11,34 & 10,26 & 0,62 \\
\hline HUN86 & 42 & $\mathrm{~F}$ & Acute & $\mathbf{0}$ & 5 & 78 & 12 & 5,37 & 3,17 & 0,91 \\
\hline HUN96 & 22 & $\mathrm{~F}$ & Acute & 5 & 23 & 53 & 23 & 7,16 & 4,48 & 1,59 \\
\hline HUN97 & 51 & $\mathrm{~F}$ & Acute & $\mathbf{0}$ & 15 & 126 & 43 & 12,19 & 5,88 & 1,01 \\
\hline HUN112 & 71 & $\mathrm{~F}$ & Acute & $\mathbf{0}$ & ND & 103 & 44 & 3,69 & 2,14 & 0,72 \\
\hline HUN113 & 25 & $\mathrm{~F}$ & Acute & $\mathbf{0}$ & 0 & 109 & 22 & 10,45 & 6,21 & 4,19 \\
\hline HUN123 & 45 & $\mathrm{~F}$ & Acute & $\mathbf{0}$ & 18 & 97 & 76 & 32,82 & 12,61 & 2,92 \\
\hline HUN126 & 36 & M & Acute & $\mathbf{0}$ & $\mathbf{0}$ & 69 & 43 & 6,79 & 3,63 & 1,81 \\
\hline HUN127 & 30 & $\mathrm{~F}$ & Acute & $\mathbf{0}$ & $\mathbf{0}$ & 75 & 12 & 8,93 & 8,09 & 1,90 \\
\hline HUN131 & 44 & $\mathrm{~F}$ & Acute & $\mathbf{0}$ & $\mathbf{0}$ & 126 & 48 & 11,12 & 7,77 & 0,49 \\
\hline HUN134 & 44 & $\mathrm{~F}$ & Acute & $\mathbf{0}$ & $\mathbf{0}$ & 80 & 19 & 7,99 & 5,84 & 1,08 \\
\hline HUN3 & 40 & M & Remission & $\mathbf{0}$ & 30 & 154 & 244 & 10,51 & 8,20 & 0,54 \\
\hline HUN28 & 36 & $\mathrm{~F}$ & Remission & 68 & 61 & NA & 213 & NA & NA & 0,88 \\
\hline HUN31 & 33 & $\mathrm{~F}$ & Remission & $\mathbf{0}$ & 29 & 153 & 275 & 6,82 & 3,41 & 0,47 \\
\hline HUN35 & 37 & $\mathrm{~F}$ & Remission & $\mathbf{0}$ & $\mathbf{0}$ & 123 & 272 & 18,70 & 10,28 & 0,86 \\
\hline HUN53 & 51 & $\mathrm{~F}$ & Remission & o & 18 & 135 & 174 & 6,85 & 4,67 & 0,57 \\
\hline HUN54 & 56 & $\mathrm{~F}$ & Remission & 104 & ND & 140 & 115 & 6,11 & 3,92 & 12,00 \\
\hline HUN58 & 46 & $\mathrm{~F}$ & Remission & 74 & ND & 136 & 158 & 5,71 & 3,31 & 0,49 \\
\hline HUN59 & 44 & $\mathrm{~F}$ & Remission & 112 & ND & 119 & 184 & 5,85 & 3,35 & 0,81 \\
\hline HUN65 & 35 & $\mathrm{~F}$ & Remission & $\mathbf{0}$ & 44 & 150 & 388 & 15,70 & 11,41 & 4,22 \\
\hline HUN70 & 47 & $\mathrm{~F}$ & Remission & 97 & 33 & NA & 213 & NA & NA & 0,73 \\
\hline HUN78 & 47 & $\mathrm{~F}$ & Remission & 0 & $\mathbf{0}$ & 134 & 210 & 7,94 & 4,64 & 0,55 \\
\hline HUN80 & 31 & M & Remission & 109 & 87 & 169 & 246 & 9,68 & 4,84 & 1,13 \\
\hline HUN81 & 21 & $\mathrm{~F}$ & Remission & 7 & 20 & 124 & 308 & 22,93 & 19,42 & 1,05 \\
\hline HUN89 & 33 & M & Remission & 0 & 23 & 156 & 260 & 5,37 & 2,84 & 0,54 \\
\hline HUN100 & 40 & $\mathrm{~F}$ & Remission & 109 & 75 & 144 & 213 & 5,88 & 3,65 & 0,47 \\
\hline HUN101 & 61 & $\mathrm{~F}$ & Remission & 79 & 65 & 123 & 196 & 6,89 & 5,49 & 0,58 \\
\hline HUN115 & 51 & $\mathrm{~F}$ & Remission & 19 & ND & 149 & 433 & 12,99 & 10,05 & 0,42 \\
\hline
\end{tabular}

NA: not available; ND: not done. 
TTP had available follow-up plasma samples. Six of them (patient's registry codes $1,15,62,68,86,127$ ) had plasma samples taken in hematological remission, after finishing the PEX series. Five of them (registry codes $68,86,126,127,131$ ) had plasma samples taken during during PEX series, before reaching hematological remission. Thus, altogether 49 EDTA-plasma samples were used for PMNE determination.

Blood samples (EDTA-anticoagulated plasma and sodium-citrate anticoagulated plasma) were taken by antecubital venipuncture or from central catheter, cells and supernatant separated by centrifugation and shipped in cooled packages ( -20 degrees of Celsius) to the Research Laboratory, where aliquots were made and stored in ultrafreezers on $<-70$ degrees of Celsius until determinations.

From each subject, informed consent was obtained and the study was approved by the institutional Ethics Committee on human research.

Determination of Plasma Polymorphonuclear Cell Elastase (PMNE) Levels and other Laboratory Parameters

A stable complex of PMNE-alpha1-proteinase-inhibitor was measured by sandwich type ELISA (QIA96, Calbiochem, Merck-Millipore, Darmstadt, Germany), according to the instructions given by the manufacturer.

The fluorigenic substrate, FRETS-VWF73, was applied for the determination of ADAMTS13 enzyme activity as described [15]. Briefly, citrated plasma was diluted 1:20 in assay buffer $(5 \mathrm{mmol} / \mathrm{l}$ Bis-Tris, $25 \mathrm{mmol} / \mathrm{L} \mathrm{CaCl}_{2}, 0.005 \%$ Tween 20, pH 6.0) and mixed with $5 \mu \mathrm{mol} / \mathrm{L}$ FRETS-VWF73 substrate solution ( $20 \mu \mathrm{l}$ each), in white 384-well plates. Fluorescence was measured at $37{ }^{\circ} \mathrm{C}$ every 2 minutes for 1 hour in Chameleon microplate reader (Hidex, Turku, Finland) equipped with a $340 \mathrm{~nm}$ excitation and a $460 \mathrm{~nm}$ emission filter. The reaction rate was calculated by linear regression analysis of fluorescence over time. A two-fold dilution series of normal human plasma (mixed from citrated plasma samples of 10 healthy blood donors) was applied as standard curve, 100\% ADAMTS13 activity was set at the reaction rate observed in the 1:20 diluted sample. The intra-assay variation coefficient was $<5 \%$, the inter-assay CV\% was $6-9 \%$ (measured at 60 and $100 \%$ activity levels). The presence of anti-ADAMTS13 inhibitors was determined by mixing 1 part of the patient's sample with 1 part of normal pooled plasma, incubation at 37 degrees of Celsius for 2 hours, and measurement of ADAMTS13 activity of the sample. The presence of ADAMTS13 inhibitors was considered if the patient's original sample had $<7 \%$ activity, and that of the mixed sample was $<50 \%$.

Levels of complement activation products $\mathrm{C} 3 \mathrm{a}$ (MicroVue C3a des$\arg$ EIA A031, mean of healthy controls $129.6 \mathrm{ng} / \mathrm{mL}$ ), Bb (MicroVue Bb EIA, A027, mean + 2SD range 0.49-1.42 $\mu \mathrm{g} / \mathrm{mL}$ ) were determined with commercial Kits (Quidel, San Diego, California, USA) according to the manufacturer's instructions in EDTA plasma samples.

\section{Statistical Analysis}

The continuous variables reported in this study showed skewed distribution and according to results of Shapiro-Willk's test deviated from the normal distribution. Therefore, for descriptive purposes the values of each measurement are given as median and 25th-75th percentile, or as numbers (percent) and non-parametric tests were used for group comparisons; continuous variables between two groups were compared with Mann-Whitney U test, for three or more groups with the Kruskal-Wallis ANOVA by ranks test, and for repeated measures with the Friedman test. Dunn's post-test was used for group comparisons after analysis of variance. Spearman's correlation coefficients were calculated by non-parametric method. Statistical analyses were carried out using STATISTICA 7.0 (StatSoft Inc., Tulsa, OK, USA) and GraphPad Prism 4.03 (GraphPad Softwares Inc., CA, USA) softwares. Two tailed $\mathrm{p}$ values were calculated and the significance level was put at a value of $\mathrm{p}<0.050$

\section{Results}

\section{Acute TTP is Associated with Increased PMNE Levels}

Table 1 shows clinical and laboratory data of the cohort. All of the patients in acute disease flare $(\mathrm{n}=21)$ were ADAMTS13 deficient (activity $<5 \%$ ) and positive for anti-ADAMTS13 inhibitors. Samples for PMNE determinations were taken before the initiation of a series of plasma exchange sessions in 13 patients, whereas for the remaining 8 cases sampling was done during the PEX series. Seventeen patients were enrolled in complete remission, 8 of them were ADAMTS13 deficient (1 patient had $7 \%$ activity and was positive for inhibitor), 8 patients had ADAMTS13 activity within the reference range, and 1 patient had moderately decreased level. Increased absolute neutrophil counts were not associated with acute TTP (Table 1), the median (IQR) values for acute patients was $6.0 \mathrm{G} / \mathrm{L}(4.4-9.7)$ whereas for patients in remission 4.7 G/L (3.4-9.1; $\mathrm{p}=0.223)$.

Acute disease was associated with significantly increased PMNE levels, whereas the group medians were similarly low in TTP patients in remission and in healthy controls (Fig. 1). Patients in remission with $(0.54 \mathrm{ng} / \mathrm{mL}, 0.53-0.86)$ or without $(0.73 \mathrm{ng} / \mathrm{mL}, 0.48-1.00)$ ADAMTS13 deficiency had similar PMNE levels $(\mathrm{p}=0.680)$. Furthermore, increased PMNE levels and deficient ADAMTS13 activity together characterized hematologically active disease (plt $<150 \mathrm{G} / \mathrm{L}$, Fig. 2, panel A). Note, that there were no patients in our cohort with non-deficient ADAMTS13 activity and decreased platelet counts. In line with this observation there was a significant association between amounts of functional ADAMTS13 inhibitors (as assessed by measuring the ADAMTS13 activity of the mixed patient/normal plasma samples) and PMNE levels (Fig. 2, panel B). There was no significant correlation between ADAMTS13 activity (measured in patient's own samples) and PMNE levels (data not shown). Similarly, no association between PMNE levels and neutrophil counts was observed $(r=-0.381, p=0.064$, data not shown) and neutrophil counts were similar in acute and remission groups, excluding the possibility of the mere reflection of higher neutrophil counts by increased PMNE levels. Finally, we investigated changes of PMNE levels during therapy. There were 5 patients with available samples before the initiation of PEX series, and during that. In 4 out of the 5 patients, PMNE levels decreased by $40-60 \%$, whereas in one patient it increased by $187 \%$. Similarly, we investigated PMNE levels in samples of 6 patients ( 4 women) with available samples collected on the day of admission, before the initiation of PEX series, and also in hematological remission at least 1 week after the last session of the PEX series. As shown in Fig. 3, achievement of remission was associated with significant reduction of circulating plasma PMNE levels in patients with TTP.

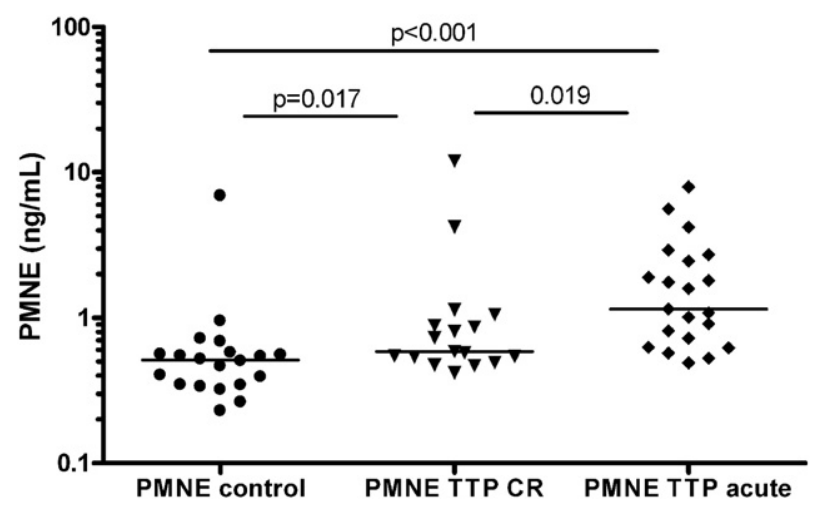

Fig. 1. Neutrophil elastase (PMNE) is marker of acute TTP. (A) Plasma neutrophil-elastasealpha1-proteinase inhibitor complex (Calbiochem, Merck-Millipore, Darmstadt, Germany) was measured in EDTA-plasma samples of healthy controls, TTP patients in complete remission) and in TTP patients with acute disease flare. Horizontal lines indicate group median, P values were obtained by Mann-Whitney test. 

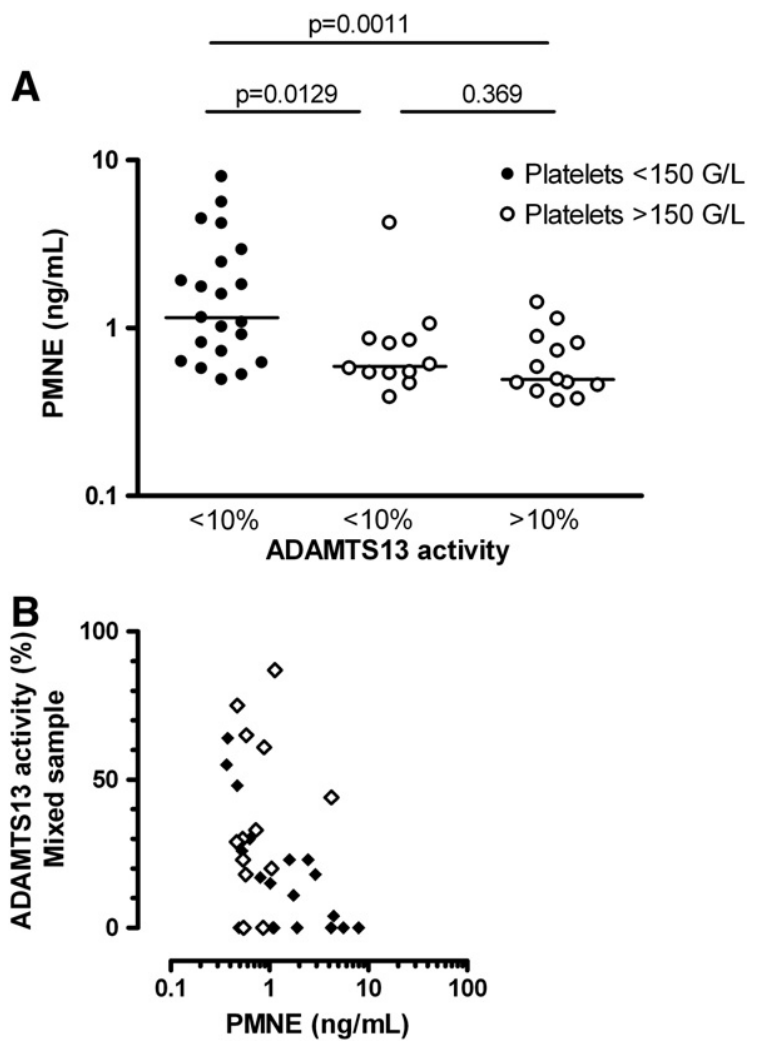

Fig. 2. (A) Elevated PMNE level together with deficient ADAMTS13 activity is characteristic for hematologically active TTP. Analysis of 46 samples of patients with hematologically active TTP (platelet below $150 \mathrm{G} / \mathrm{L}$ ) or in hematological remission (platelet above $150 \mathrm{G} / \mathrm{L}$ ), as stratified by the presence of ADAMTS13 deficiency (activity $<5 \%$ ). P values were obtained by Mann-Whitney test. (B) Correlation between functional ADAMTS13 inhibitor and PMNE concentrations. Inhibitors against ADAMTS13 were assessed in 33 samples of patients with TTP by mixing studies as described in the Materials and Methods section. Samples taken in acute TTP are marked with closed symbols, whereas those taken in remission are marked with open symbols. Horizontal lines indicate group median, correlation coefficient with p value was calculated by Spearman's non-parametric method: pooled analysis $\mathrm{r}=-0.428, \mathrm{p}=0.013$; acute TTP: $\mathrm{r}=-0,547, \mathrm{p}=0.012$; TTP in remission: $\mathrm{r}=0.171, \mathrm{p}=0.577$ ).

Association between PMNE Levels, Activity Markers of TTP and Complement Activation Products

Next, correlations between TTP activity markers and PMNE levels were analyzed. The amount of PMNE showed inverse correlation to

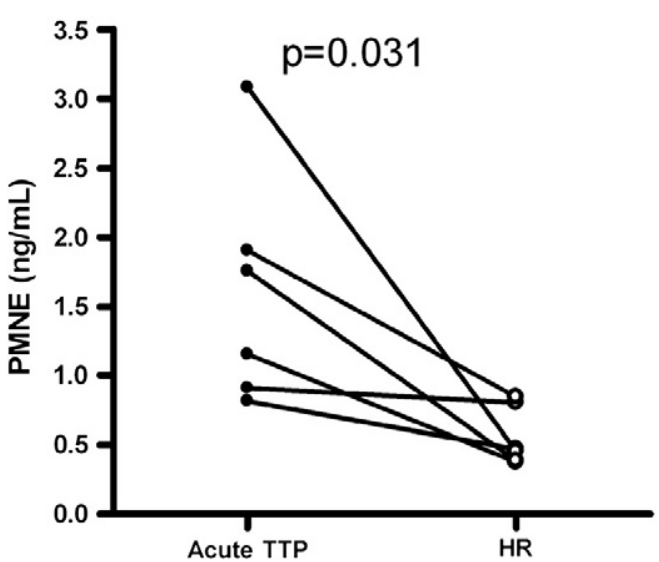

Fig. 3. Changes of plasma neutrophil elastase (PMNE) levels during treatment of acute disease flare in TTP. Comparison of PMNE concentrations in plasma from 6 patients ( 4 women) with TTP collected at the presentation with acute disease (acute TTP) or in hematological remission (HR). P value was obtained by Wilcoxon test. platelet count and hemoglobin levels in the whole TTP cohort (Fig. 4, panel A and B). Fourteen patients with acute TTP received packed red blood cells before sampling for PMNE determinations. The significant inverse association is present between PMNE and hemoglobin levels if these subjects are excluded form the analysis presented on Fig. 4B $(\mathrm{r}=-0.427, \mathrm{p}=0.037)$. Result of stratified correlation analysis (although underpowered due to low patient numbers) is presented in legend for Fig. 4.

In a subset of these patients levels of complement factors and activation products have been measured previously. Increased levels of C3a and terminal pathway complex (TCC) were observed in acute TTP [10]. Therefore, we analyzed if any of the complement factors or activation products show association with activity markers of neutrophils. As shown in Fig. 5, concentrations of the activity marker of the alternative pathway convertase's enzymatic component Factor B $(\mathrm{Bb}, \mathrm{r}=0.392, \mathrm{p}=0.015)$ and anaphylatoxin $\mathrm{C} 3 \mathrm{a}(\mathrm{r}=0.367, \mathrm{p}=$ 0.024 ) showed significant, positive correlation to PMNE levels. No other significant correlation between complement components ( $\mathrm{C} 3$, Factors B, H, I, r $=-0.171,-0.287,0.015,0.255$, respectively, all p $>0.05$ ) or activation products (C1r-C1s-C1-inhibitor, C4d, C3bBbP, TCC, 0.025, 0.058, 0.017, 0.199, respectively, all $\mathrm{p}>0.05$ ) and PMNE concentration was observed.
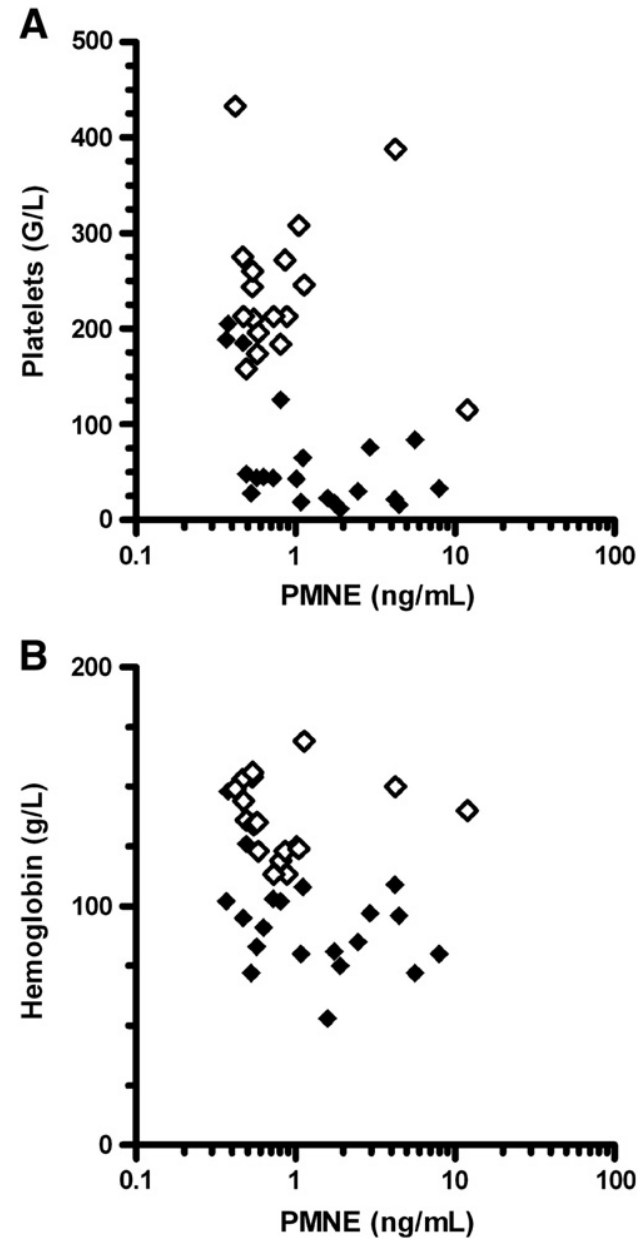

Fig. 4. Association of plasma neutrophil elastase (PMNE) levels with disease activity markers in TTP. Correlation coefficients and p values between plasma PMNE levels and platelet counts (A) or hemoglobin levels (B) were calculated by the Spearman non-parametric method (Panel A, pooled analysis: $r=-0.483, p=0.006$; acute TTP: $-0.521, p=0.015$; TTP in remission: $r=-0.086, p=0.743$; Panel $B$, pooled analysis: $\mathrm{r}=-0.382, \mathrm{p}=0.018$, acute TTP: $-0.353, \mathrm{p}=0.116$; TTP in remission: $\mathrm{r}=$ $-0.257, \mathrm{p}=0.318$ ). Samples taken in acute TTP are marked with closed symbols, whereas those taken in remission are marked with open symbols. 
A
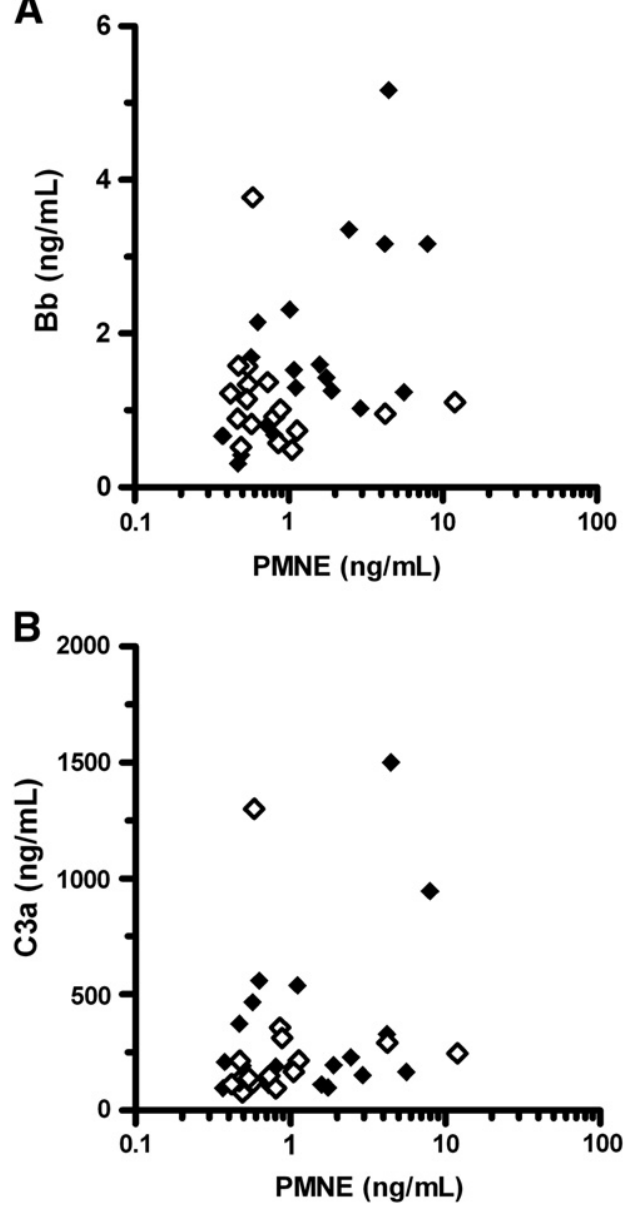

Fig. 5. Association of plasma neutrophil elastase (PMNE) levels with complement activation products in TTP. Correlation coefficients and $p$ values between plasma PMNE levels and activated factor B (Bb) (panel A) or anaphylatoxin C3a (panel B) levels were calculated by the Spearman non-parametric method (Panel A $r=0.392, p=0.015$; Panel $\mathrm{B} \mathrm{r}=0.367, \mathrm{p}=0.024)$. Samples taken in acute TTP are marked with closed symbols, whereas those taken in remission are marked with open symbols.

\section{Discussion}

Here we report on two novel findings. First, in a well-characterized, homogenous ADAMTS13-deficient, inhibitor positive cohort of TTP patients elevated neutrophil activation marker, PMNE, was shown to be increased in acute disease flare. PMNE levels were directly related to disease activity markers hemoglobin and platelet count, and correlated with the amounts of functional ADAMTS13 inhibitor. Second, according to the presented data, neutrophil- and complement activation are present parallel in acute TTP and correlate to each other.

The potential link between thrombotic microangiopathy and neutrophils was first studied and characterized in E. coli caused typical HUS. Increased initial neutrophil count was shown to be predictive for bad outcome in D + HUS [16]. Further, neutrophil markers (elastase, myeloperoxidase and IL-8) were elevated and linked to endothelial cell damage and thrombin activity in typical HUS [17]. Similar observations have been reported for a few diarrhea negative HUS patients [18]. Recently, elevated myeloperoxidase and circulating DNA levels were shown in patients with various forms of TMA (ADAMTS13 deficient TTP, D + HUS, tumor-associated TMA and TMA of with unknown etiology). Increased plasma DNA and MPO levels together with ADAMTS13 deficiency characterized the acute disease state in patients with acquired TTP. Authors concluded that circulating DNA and histones in patients with TMA could have originated from neutrophil extracellular traps (NETs) [14].
Neutrophils release processed chromatin termed neutrophil extracellular traps (NETs) to trap and kill pathogens [19]. NETs are implicated in immune defense [20], sepsis [21] and autoimmunity [22]. NET is formed by a DNA-histones scaffold that contains granule proteins such as elastase and myeloperoxidase, as well as antimicrobial peptides [23]. Results obtained in PMNE knock-out mice showed that these animals do not form NETs in a pulmonary model of bacterial infection [24]. These and other studies [24] collectively demonstrated that PMNE is essential for the initiation of NET formation and is externalized together with NETs after stimulation of neutrophils. Therefore, based on our results we conclude that the increased PMNE levels in acute TTP may originate from neutrophils in a process of cell activation and NET release. Our observations independently confirm the results of Fuchs et al., regarding the contribution of neutrophil activation to the pathogenesis of acute TMAs, and its correlation to disease activity.

Activation of neutrophils, as assessed by a specific biomarker, elastase, is characteristic for hematologically active TTP. Patients with $>150 \mathrm{G} / \mathrm{L}$ platelet counts and deficient ADAMTS13 activity had similar mean PMNE level to those in remission without ADAMTS13 deficiency (Fig. 2), and also similar to healthy controls (Fig. 1). Furthermore, treatment of acute TTP by a series of PEX sessions resulted decrease of PMNE levels in the majority of patients during PEX, whereas the reduction was significant (Fig. 3) after reaching of hematological remission. These results support the multiple hit concept in the pathogenesis of TMAs, specifically, TTP. Acute TMA flares often follow infections or precipitate during or after pregnancy and neutrophil activation is known to be increased in these clinical states [9]. In genetically (rare or common variants in ADAMTS13) or immunologically (ADAMTS13 inhibitors) predisposed individuals, activation of neutrophils and release of NETs may precipitate acute TTP by multiple mechanisms. As shown in mouse model, DNA and histones stimulate thrombosis and promote cytotoxicity [25-27]. In addition, reactive oxygen species released by activated neutrophils have prothrombotic effect, mediated in part by inhibition of VWF cleavage by ADAMTS13 [28]. Finally, leukocyte proteases including elastase cleave von Willebrand factor at or near the ADAMTS13 cleavage site and may therefore participate in the proteolytic regulation of VWF [29].

Furthermore, NETs may activate complement leading to C3b deposition to NET components and generation of C5a [30]. Previously we [10] and others [11] documented the activation of the classical/lectin, the alternative and the terminal pathways of complement in TTP. Our current results indicate the association between PMNE and C3 activation (C3a), and the presence of NETs may be a potential link between these factors. The presence of correlation between PMNE and Bb levels point to the initiation of alternative amplification loop extending complement activation. Complement activation attracts and activates neutrophils $[31,32]$, and in turn may exacerbate NET release, initiating a positive feed-back loop. These observations are in line with the recent report on the association among circulating nucleosomes, activated neutrophils (as indicated by increased neutrophil elastase- $\alpha 1$-antitrypsin complexes), and presence of deep vein thrombosis [33]. Taken together, evolutionarily conserved innate mechanisms acting in concert may stimulate thrombosis, endothelial damage $[34,35]$ and contribute to the precipitation of acute TTP.

Currently PMNE measurement is possible only by manual immuno- and enzymatic assays, therefore this restricted availability and relatively high costs limit its potential clinical application. However, if these observations can be repeated in independent cohorts markers of neutrophil activation may potentially help to stratify patients between therapeutic modalities and to guide time and frequency of plasma exchange treatment.

We acknowledge potential limitations of our study. TTP is a rare disorder, and we were unable to enrol more patients in a reasonable short time-frame allowing the correct analysis of elastase and neutrophil activation. Therefore, due to the low number of patients some of the 
analysis presented here are underpowered, there is a possibility for the presence of false negative or false positive conclusions in the results (especially for the correlation analysis), and therefore some of the conclusions have to be taken as preliminary, until independent confirmation is published.

In conclusion, we report the association of increased plasma neutrophil elastase levels with acute TTP. Increased PMNE levels were directly related to hematologically active TTP, to functional ADAMTS13 inhibitors, disease activity markers of acute TTP (hemoglobin concentrations and platelet counts) and complement activation markers of the alternative pathway. Effective treatment of an acute TTP episode resulted in marked decrease in PMNE levels. Our data lend credence to the hypothesis that neutrophil extracellular traps may be released in acute TTP and may potentially contribute to the pathophysiology of this disease. We identified complement activation products associated with high PMNE levels indicating for the presence of a potential positive feed-back loop between innate mechanisms behind the precipitation of acute TTP.

\section{Conflicts of Interest Statement}

\section{None to Declare.}

\section{Acknowledgements}

The authors are grateful for the patients for their participation in the study and for the excellent technical support from Szigeti Antalné, Márta Kókai, Zsuzsanna Szendrei and Holeczky Rudolfné. The study was financially supported by a grant from National Research Fund of Hungary (T100687 to ZP). The authors are grateful for the expert medical support and sharing of clinical data to Krisztina Madách, Csaba Bereczki, Attila J Szabó, György S Reusz, Gáspár Radványi, and Klára Gadó.

\section{Addendum}

Study concept and design: M Réti, P Farkas and Z Prohászka. Experimental procedures: $\mathrm{B}$

Mikes and G Sinkovits and D Csuka. Acquisition of data: M Réti, P Farkas, K Rázsó, Á

Schlammadinger, J Demeter, G Domján, Analysis and interpretation of data: Z Prohászka, D

Csuka, M Réti, P Farkas Critical writing of the manuscript: M Réti, P Farkas, Z Prohászka

Critical revision of the manuscript for important intellectual content: B Mikes, M Réti, P

Farkas, D Csuka, K Rázsó, Á Schlammadinger, J Demeter, G Domján, Obtaining funding: Z

Prohászka Study supervision: M Réti, Z Prohászka

\section{References}

[1] Chapman K, Seldon M, Richards R. Thrombotic microangiopathies, thrombotic thrombocytopenic purpura, and ADAMTS-13. Semin Thromb Hemost 2012;38(1):47-54.

[2] Clark WF. Thrombotic microangiopathy: current knowledge and outcomes with plasma exchange. Semin Dial 2012;25(2):214-9.

[3] Kremer Hovinga JA, Lammle B. Role of ADAMTS13 in the pathogenesis, diagnosis, and treatment of thrombotic thrombocytopenic purpura. Hematology Am Soc Hematol Educ Program 2012;2012:610-6.

[4] Tsai HM. von Willebrand factor, shear stress, and ADAMTS13 in hemostasis and thrombosis. ASAIO J 2012:58(2):163-9.

[5] Fujimura Y, Matsumoto M, Isonishi A, Yagi H, Kokame K, Soejima K, et al. Natural history of Upshaw-Schulman syndrome based on ADAMTS13 gene analysis in Japan. Thromb Haemost 2011;9(Suppl 1):283-301.

[6] Moatti-Cohen M, Garrec C, Wolf M, Boisseau P, Galicier L, Azoulay E, et al. Unexpected frequency of Upshaw-Schulman syndrome in pregnancy-onset thrombotic thrombocytopenic purpura. Blood 2012;119:5888-97.
[7] Peyvandi F, Lavoretano S, Palla R, Feys HB, Vanhoorelbeke K, Battaglioli T, et al. ADAMTS13 and anti-ADAMTS13 antibodies as markers for recurrence of acquired thrombotic thrombocytopenic purpura during remission. Haematologica 2008;93:232-9.

[8] Chaturvedi S, Carcioppolo D, Zhang L, McCrae KR. Management and outcomes for patients with TTP: analysis of 100 cases at a single institution. Am J Hematol 2013.

[9] Falter T, Alber KJ, Scharrer I. Long term outcome and sequelae in patients after acute thrombotic thrombocytopenic purpura episodes. Hamostaseologie 2013;33(2):113-20.

[10] Reti M, Farkas P, Csuka D, Razso K, Schlammadinger A, Udvardy ML, et al. Complement activation in thrombotic thrombocytopenic purpura. J Thromb Haemost 2012;10:791-8.

[11] Westwood ${ }^{1}$ J-P, Langley ${ }^{1}$ K, Heelas ${ }^{1}$ E, Machin ${ }^{1}$ S, Scully ${ }^{2}$ M. Complement activation in thrombotic thrombocytopenic purpura. Mol Immunol December 15 2013;56(3):1.

[12] Derzsy Z, Prohaszka Z, Rigo Jr J, Fust G, Molvarec A. Activation of the complement system in normal pregnancy and preeclampsia. Mol Immunol 2010;47:1500-6.

[13] Hung TH, Chen SF, Lo LM, Li MJ, Yeh YL, Hsieh TT. Myeloperoxidase in the plasma and placenta of normal pregnant women and women with pregnancies complicated by preeclampsia and intrauterine growth restriction. Placenta 2012;33:294-303.

[14] Fuchs TA, Kremer Hovinga JA, Schatzberg D, Wagner DD, Lammle B. Circulating DNA and myeloperoxidase indicate disease activity in patients with thrombotic microangiopathies. Blood 2012;120:1157-64.

[15] Gombos T, Mako V, Cervenak L, Papassotiriou J, Kunde J, Harsfalvi J, et al. Levels of von Willebrand factor antigen and von Willebrand factor cleaving protease (ADAMTS13) activity predict clinical events in chronic heart failure. Thromb Haemost 2009;102:573-80.

[16] Walters MD, Matthei IU, Kay R, Dillon MJ, Barratt TM. The polymorphonuclear leucocyte count in childhood haemolytic uraemic syndrome. Pediatr Nephrol 1989;3:130-4.

[17] Ishikawa N, Kamitsuji H, Murakami T, Nakayama A, Umeki Y. Plasma levels of granulocyte elastase-alpha1-proteinase inhibitor complex in children with hemolytic uremic syndrome caused by verotoxin-producing Escherichia coli. Pediatr Int 2000;42:637-41.

[18] Fitzpatrick MM, Shah V, Filler G, Dillon MJ, Barratt TM. Neutrophil activation in the haemolytic uraemic syndrome: free and complexed elastase in plasma. Pediatr Nephrol 1992;6:50-3.

[19] Brinkmann V, Reichard U, Goosmann C, Fauler B, Uhlemann Y, Weiss DS, et al. Neutrophil extracellular traps kill bacteria. Science 2004;303:1532-5.

[20] Brinkmann V, Zychlinsky A. Neutrophil extracellular traps: is immunity the second function of chromatin? J Cell Biol 2012;198(5):773-83.

[21] Clark SR, Ma AC, Tavener SA, McDonald B, Goodarzi Z, Kelly MM, et al. Platelet TLR4 activates neutrophil extracellular traps to ensnare bacteria in septic blood. Nat Med 2007;13:463-9.

[22] Kessenbrock K, Krumbholz M, Schonermarck U, Back W, Gross WL, Werb Z, et al. Netting neutrophils in autoimmune small-vessel vasculitis. Nat Med 2009;15:623-5.

[23] Urban CF, Ermert D, Schmid M, Abu-Abed U, Goosmann C, Nacken W, et al. Neutrophil extracellular traps contain calprotectin, a cytosolic protein complex involved in host defense against Candida albicans. PLoS Pathog 2009;5:e1000639.

[24] Papayannopoulos V, Metzler KD, Hakkim A, Zychlinsky A. Neutrophil elastase and myeloperoxidase regulate the formation of neutrophil extracellular traps. J Cell Biol 2010;191:677-91.

[25] Massberg S, Grahl L, von Bruehl ML, Manukyan D, Pfeiler S, Goosmann C, et al. Reciprocal coupling of coagulation and innate immunity via neutrophil serine proteases. Nat Med 2010;16:887-96.

[26] Brill A, Fuchs TA, Savchenko AS, Thomas GM, Martinod K, De Meyer SF, et al. Neutrophil extracellular traps promote deep vein thrombosis in mice. J Thromb Haemost 2012:10:136-44.

[27] Xu J, Zhang X, Pelayo R, Monestier M, Ammollo CT, Semeraro F, et al. Extracellular histones are major mediators of death in sepsis. Nat Med 2009;15:1318-21.

[28] Chen J, Fu X, Wang Y, Ling M, McMullen B, Kulman J, et al. Oxidative modification of von Willebrand factor by neutrophil oxidants inhibits its cleavage by ADAMTS13. Blood 2010;115:706-12.

[29] Raife TJ, Cao W, Atkinson BS, Bedell B, Montgomery RR, Lentz SR, et al. Leukocyte proteases cleave von Willebrand factor at or near the ADAMTS13 cleavage site. Blood 2009;114:1666-74.

[30] Leffler J, Martin M, Gullstrand B, Tyden H, Lood C, Truedsson L, et al. Neutrophil extracellular traps that are not degraded in systemic lupus erythematosus activate complement exacerbating the disease. J Immunol 2012;188:3522-31.

[31] Jagels MA, Daffern PJ, Hugli TE. C3a and C5a enhance granulocyte adhesion to endothelial and epithelial cell monolayers: epithelial and endothelial priming is required for C3a-induced eosinophil adhesion. Immunopharmacology 2000;46(3):209-22.

[32] Peng Q, Li K, Sacks SH, Zhou W. The role of anaphylatoxins C3a and C5a in regulating innate and adaptive immune responses. Inflamm Allergy Drug Targets 2009;8:236-46.

[33] van Montfoort ML, Stephan F, Lauw MN, Hutten BA, Van Mierlo G], Solati S, et al. Circulating nucleosomes and neutrophil activation as risk factors for deep vein thrombosis. Arterioscler Thromb Vasc Biol 2013;33(1):147-51.

[34] Karpman D, Tati R. Complement activation in thrombotic microangiopathy. Hamostaseologie 2013;33(2):96-104.

[35] Noris M, Mescia F, Remuzzi G. STEC-HUS, atypical HUS and TTP are all diseases of complement activation. Nat Rev Nephrol 2012;8(11):622-33. 